Published in final edited form as:

Hum Genet. 2013 September ; 132(9): 1015-1025. doi:10.1007/s00439-013-1313-4.

\title{
Role of TRAV Locus in Low Caries Experience
}

\begin{abstract}
Jessica Briseño-Ruiz ${ }^{1}$, Takehiko Shimizu ${ }^{2}$, Kathleen Deeley ${ }^{1}$, Piper M. Dizak ${ }^{1}$, Timothy D. Ruff ${ }^{1}$, Italo M. Faraco Jr. ${ }^{1}$, Fernando A. Poletta ${ }^{3,4}$, João A. Brancher ${ }^{5}$, Giovana D.

Pecharki $^{5}$, Erika C. Küchler ${ }^{1}$, Patricia N. Tannure ${ }^{6}$, Andrea Lips ${ }^{7}$, Thays C.S. Vieira ${ }^{7}$, Asli

Patir $^{8}$, Mine Koruyucu ${ }^{9}$, Juan C. Mereb ${ }^{10}$, Judith M. Resick ${ }^{1}$, Carla A. Brandon ${ }^{1}$, Ariadne

Letra $^{11}$, Renato M. Silva ${ }^{11}$, Margaret E. Cooper ${ }^{1}$, Figen Seymen ${ }^{9}$, Marcelo C. Costa ${ }^{6}$, José

M. Granjeiro 7,12 , Paula C. Trevilatto ${ }^{5}$, lêda M. Orioli ${ }^{13}$, Eduardo E. Castilla ${ }^{3,4}$, Mary L.

Marazita $^{1,14}$, and Alexandre R. Vieira ${ }^{1,15}$

${ }^{1}$ Department of Oral Biology, University of Pittsburgh, Pittsburgh, PA

${ }^{2}$ Department of Pediatric Dentistry, Nihon University of Dentistry at Matsudo, Matsudo Chiba, Japan
\end{abstract}

${ }^{3}$ ECLAMC (Latin American Collaborative Study of Congenital Malformations) at CEMIC (Center for Medical Education and Clinical Research), Buenos Aires, Argentina

${ }^{4}$ ECLAMC at INAGEMP-CNPq (National Institute of Population Medical Genetics) in Department of Genetics, Oswaldo Cruz Foundation; Rio de Janeiro, Brazil

${ }^{5}$ Center for Health and Biological Sciences, Pontifical Catholic University of Paraná (PUCPR), Curitiba, Brazil

${ }^{6}$ Department of Pediatric Dentistry and Orthodontics, Federal University of Rio de Janeiro, Rio de Janeiro, Brazil

${ }^{7}$ Biology Institute, Clinical Research Unit, Fluminense Federal University, Niterói, RJ

${ }^{8}$ Department of Pedodontics, Istanbul Medipol University, Istanbul, Turkey

${ }^{9}$ Department of Pedodontics, Istanbul University, Istanbul, Turkey

${ }^{10}$ ECLAMC at Hospital de Area El Bolsón, Río Negro, Argentina

${ }^{11}$ Department of Endodontics, School of Dentistry, and Pediatric Research Center, Medical

School, University of Texas Health Science Center at Houston, Houston, TX

${ }^{12}$ INMETRO, Duque de Caxias, RJ, Brazil

${ }^{13}$ ECLAMC at INAGEMP-CNPq (National Institute of Population Medical Genetics) in Department of Genetics, Institute of Biology, Center of Health Sciences; Federal University of Rio de Janeiro; Rio de Janeiro, Brazil

${ }^{14}$ Center for Craniofacial and Dental Genetics, Department of Human Genetics, and Clinical and Translational Science, University of Pittsburgh, Pittsburgh, PA

${ }^{15}$ Center for Craniofacial and Dental Genetics and Department of Pediatric Dentistry, School of Dental Medicine, and Clinical and Translational Science, University of Pittsburgh, Pittsburgh, PA

\section{Abstract}

Corresponding Author: Alexandre R. Vieira, 614 Salk Hall, Dept. Oral Biology, School of Dental Medicine, University of Pittsburgh, Pittsburgh, PA, 15261, USA. arv11@ pitt.edu. Phone \#: 1-412-383-8972. FAX \#: 1-624-3080.

The authors have declared that no competing interests exist. 
Caries is the most common chronic, multifactorial disease in the world today; and little is still known about the genetic factors influencing susceptibility. Our previous genome- wide linkage scan has identified five loci related to caries susceptibility: 5q13.3, 13q31.1, 14q11.2, 14q 24.3, and Xq27. In the present study, we fine mapped the 14q11.2 locus in order to identify genetic contributors to caries susceptibility. Four hundred seventy-seven subjects from 72 pedigrees with similar cultural and behavioral habits and limited access to dental care living in the Philippines were studied. An additional 387 DNA samples from unrelated individuals were used to determine allele frequencies. For replication purposes, a total of 1,446 independent subjects from four different populations were analyzed based on their caries experience (low versus high). Fortyeight markers in 14q11.2 were genotyped using TaqMan chemistry. Transmission disequilibrium test was used to detect overtransmission of alleles in the Filipino families, and chi-square, Fisher's exact and logistic regression were used to test for association between low caries experience and variant alleles in the replication data sets. We finally assessed the mRNA expression of TRAV4 in the saliva of 143 study subjects. In the Filipino families, statistically significant associations were found between low caries experience and markers in TRAV4. We were able to replicate these results in the populations studied that were characteristically from underserved areas. Direct sequencing of 22 subjects carrying the associated alleles detect one missense mutation (Y30R) that is predicted to be probably damaging. Finally, we observed higher expression in children and teenagers with low caries experience, correlating with specific alleles in TRAV4. Our results suggest TRAV4 may have a role in protecting against caries.

\section{Introduction}

Caries is still a major problem in most industrialized countries, affecting 60 to $90 \%$ of schoolchildren and the vast majority of adults (World Health Organisation 2003). The etiology is complex and multifactorial with contributions from external factors like: the host, oral microbial flora, type of diet, shared behaviors, practices and habits within family, and pressures from society (Fisher-Owens et al. 2007).

Currently, identifing children at risk for caries prior to the occurrence of the disease still depends on classic methods, including application of diet questionnaires, inspection of oral hygiene level, and detection of Streptococcus mutans in saliva. However, these attempts have had limited success in determining caries risk at the population level, and the most promising methods reach sensitivity and specificity of around $80 \%$ (Gao et al. 2010). Previous caries experience continues to be the best predictor for future disease (Powell 1998). A child's resistance or susceptibility to caries can occur, regardless of exposure to external risk factors. These facts suggest that there is biological influence on disease susceptibility, likely controlled by genetic factors of the host.

Although caries is a complex disease, studies on twins and families have provided strong evidence for a role of genetic inheritance for caries, with an estimated genetic contribution to caries development of 40 to 60\% (Conry et al. 1993; Bretz et al. 2005; Bretz et al. 2006; Wang et al. 2010). The importance of genetic factors in caries is also supported by animal studies that have identified a few chromosomal loci (in chromosomes 1, 2, 7, and 8) for caries susceptibility (Suzuki and Kurihara 1998; Nariyama et al. 2004). Regarding the mode of inheritance, both a mouse cross-breeding study (Nariyama et al. 2004) and a family segregation analysis in humans (Werneck et al. 2011) suggest a major gene dominant effect for caries.

Our previous genome-wide linkage scan for caries in 624 individuals from 46 Filipino families identified three loci for low caries susceptibility (5q13.3, 14q11.2, and Xq27.1) and two loci for high caries susceptibility (13q31.1 and 14q24.3) (Vieira et al. 2008a). Recently, our group showed that the $5 \mathrm{q} 13.3$ locus may be related to caries susceptibility through genes 
related to immune response (Shimizu et al. 2013). The 14q11.2 locus had significant results under a recessive model (Vieira et al. 2008a). Our hypothesis then was that genetic factors located in 14q11.2 underlie biological mechanisms that influence low caries experience in humans. Here, we present the fine mapping of the 14q11.2 locus and the identification of a gene that may be relevant for caries susceptibility.

\section{Materials and Methods}

\section{Study Subjects}

The study sites, subject recruitment and DMFT/dmft (Decayed, Missing due to caries, Filled Teeth) data collection have been described in our original genome-wide linkage study (Vieira et al. 2008a), but the number of families was increased from 46 to 72 for further fine mapping. DNA samples were extracted from peripheral blood according to standard protocols. In an attempt to reduce the influence of environmental factors as potential confounders in this study, the sample population consisted of 477 subjects ( 224 females and 253 males) from 72 pedigrees living in the same area in the Philippines. An additional 387 DNA samples from unrelated individuals from the same area collected during preliminary assessments of oral health needs were available for determining allele frequencies. Families included were part of exisiting studies of other craniofacial defects (Murray et al. 1997). The mean age of the subjects was 25.8 years and ranged from 2 to 72 years of age and the mean DMFT/dmft score was 9.7 and ranged from 0 to 32 (Table 1). This study protocol was approved by the University of Pittsburgh and H.O.P.E. Foundation International Institutional Review Boards, and appropriate written informed consent was obtained from all participants. Age appropriate assent documents were used for children between 7 and 14 years of age with written informed consent obtained from the parents as well. Caries experience data (DMFT/dmft scores; World Health Organization 1997) were collected by a single examiner who was calibrated by one of the authors (A.R.V.). Intraexaminer agreement was assessed by a second clinical exam in ten families after two weeks, with a $\kappa$ of 1.0. The criteria of caries experience level based on age and DMFT scores, and DMFT cut-offs used for statistical analysis were the same used in the original genome-wide linkage study (Table 2) (Vieira et al. 2008a).

\section{Association Analyses}

The 14q11.2 locus covers a 1-LOD interval (upstream and downstream) from the point with the maximum LOD score on chromosome 14 from our previous work in the Philippines (Vieira et al. 2008a). We selected SNPs (single nucleotide polymorphisms) to fine map the 14q11.2 region, which covers about 7.3 million base pairs and spans 128 genes, by using the data from the International HapMap Project on Caucasians and Chinese (www.hapmap.org), viewed through the software Haploview (Barrett et al. 2005). We selected 48 SNPs in the $14 q 11.2$ region based on pairwise linkage disequilibrium properties, haplotype blocks, and structure of the genes present in the region. Genotyping was performed using Taqman chemistry on an ABI 7900HT real-time PCR equipment. Endpoint analysis was performed using the ABI SDS software (Applied Biosystems, CA, USA). Association between caries experience and the SNPs was tested with the transmission disequilibrium test (TDT) as implemented in FBAT (Family-Based Association Test) (Horvath et al., 2001). Correction for multiple comparisons in single marker analyses was performed using the SNP spectral decomposition (SpD) method (Nyholt 2004). Significance was set at $\mathrm{p}<0.00035$ by the SpD method. Calculations of linkage disequilibrium were computed with the Graphical Overview of Linkage Disequilibrium (GOLD) software (Abecasis and Cookson 2000). 


\section{Replication Dataset}

The replication dataset consisted of 1,446 individuals from four populations including Turkish, Guatemalan, and two Brazilian cohorts (Table 1). Caries experience was defined as described in Table 2, taking into consideration age of subjects (Vieira et al. 2008). Details regarding the demographics and caries experience of the four study groups are presented in Table 1. With the exception of Brazil, drinking water in the regions where samples originated is not artificially fluoridated. DNA samples from the replication dataset were extracted from whole saliva collected in Oragene kits (DNA Genotek, Inc., Ottawa, Ontario, Canada) according to the manufacturer's instructions. Subjects were asked to spit 2 to $4 \mathrm{ml}$ of saliva whitin 5 to 10 minutes. Absorbing sponges provided by the manufacturer were used for children younger than 7 years of age.

These replication experiments targeted SNPs showing suggestive association with caries experience in the Filipino dataset. When the allele frequency was low in a specific replication group, we selected additional markers in the same region. Hardy-Weinberg equilibrium tests were performed to test for deviations in the genotype and allele distributions. Distribution of genotypes and allele frequencies in the Turkish cohort was tested by chi-square. For the Guatemalan and Brazilian cohorts, we used logistic regression analysis and haplotype analysis [as implemented in PLINK (Purcell et al. 2007)] to investigate main-effect models and predict caries status. Since the definitions of caries experience are based on age, there was no need to adjust for age in the regression analysis. For genetic association analyses, a nominal p-value $\leq 0.05$ was considered statistically significant.

Turkey-The study sample from Istanbul, Turkey, consisted of 172 unrelated children (93 females and 79 males) from 3 to 6 years of age. All children younger than 6 years of age visiting the Pedodontics Department for treatment during 2007 were invited to participate in the study. Ninety children had a dmft score of more than four and 82 children were cariesfree (Patir et al. 2008). Children with dmft scores between 1 and 3 were not included. Both Istanbul University and University of Pittsburgh Institutional Review Boards approved the study of these samples and appropriate written informed consent was obtained from the parents of all participants.

Guatemala-The cohort from Tiquisate, Guatemala consisted of 230 DNA samples from unrelated individuals (161 females; mean DMFT 8.3 \pm 7.5 , and 69 males; mean DMFT 6.6 \pm 6.5 , mean age of 31 years) who participated in studies conducted by the University of Pittsburgh Center for Craniofacial and Dental Genetics, specifically a 2006 research trip in collaboration with a Children of the Americas medical mission. As part of the research protocol the cohort received a dental examination (Deeley et al. 2008). These samples were collected with the approval of both the University of Pittsburgh Institutional Review Board and the Oversight Ethics Committee of the Hospital Nacional de Tiquisate, and all subjects gave informed, written consent.

Brazil-Two sample data sets from Brazil were available for this study. The first consisted of 539 unrelated children living in Curitiba (261 females and 278 males) with a mean age of 12 years (between 10 and 14 years) and mean DMFT of $1.5 \pm 1.9$. These children were all $5^{\text {th }}, 6^{\text {th }}$, or $7^{\text {th }}$ grades students of twelve public schools during the year 2006 (Brancher et al. 2011) to obtain a representative sample of Curitiba county. These samples were used with the approval of both the Pontifical Catholic University of Paraná and the University of Pittsburgh Institutional Review Boards. Age appropriate assent documents were used for all children and informed, written consent was obtained from the parents. The second group consisted of 501 unrelated subjects living in Rio de Janeiro participating in studies of other 
craniofacial anomalies (236 females and 265 males) with mean age of 9 years (between 2 and 21 years) and mean DMFT of $2.4 \pm 3.0$, ascertained for studies of craniofacial anomalies (Tannure et al. 2012). These samples were used with the approval of both the Federal University of Rio de Janeiro and the University of Pittsburgh Institutional Review Boards. Age appropriate assent documents were used for children between 7 and 14 years and informed; written consent was obtained from the child, as well as from the parents.

\section{Caries Assessment}

Caries experience data (DMFT/dmft) was collected according to the Would Health Organisation protocol of 1997 (World Health Organisation 1997). In brief, visible lesions in dentin, as well as visible active lesions in enamel (white spots) were scored as decayed. An explorer was gently used for assessing the smothness of tooth surfaces. Gauze was used to dry and clean teeth prior to exam. Artificial light and a dental operatory were used for all evaluations, with the exception of the Philippines and Guatemala, where a bed was available for subjects to lay down. Exam calibrations were performed according to the following protocol: First, the calibrator presented to the examiner(s) the criteria for caries detection, showing pictures of several situations to be observed in the exam (sound and decayed tooth surfaces, filled teeth with and without secondary lesions, missing teeth due to caries or due to other reasons) and discussing each of these situations in a session that lasted one to two hours. Next, the calibrator and examiner(s) examined 10 to 20 subjects and discussed each case. In the case of data from Turkey, one of the authors (A.P.) carried out the clinical examination after being calibrated by an experienced specialist (F.S.). The intra-examiner agreement was assessed by a second clinical exam in $10 \%$ of the sample after 2 weeks, with a $\kappa$ of 1.0. In the cases of Argentina and Guatemala, data was collected by one single experienced specialist examiner (A.R.V.). Subjects in these projects are seen over a period of no longer than three to five days and intra-examiner agreement data could not be generated. Samples from Rio de Janeiro, Brazil, were collected by two examiners (E.C.K. and P.N.T.) and calibrated by an experienced specialist (M.C.C.). The intraexaminer agreement was assessed by a second clinical exam in 20 children after 2 weeks, with a $\kappa$ of 0.99 . Cohen's kappa values for agreement between examiners were 0.91. Finally, caries experience data from Curitiba, Brazil, were collected by two examiners (J.A.B. and G.D.P.) and calibrated by an experienced specialist (P.C.T.). Inter- and intra-examiner reproducibility was taken on $10 \%$ of the sample and $\kappa$ were 0.93 for inter- and 0.99 for intra-examiner reliability.

\section{Mutation Analysis}

We carried out mutation analysis of TRAV4 since SNPs flanking the gene showed significant or suggestive association with caries experience in the Filipinos, Turkish, Guatemalans, and Brazilians.

Twenty-two samples from individuals with low caries experience carrying two copies of the associated SNP alleles were selected for sequencing all exons and intron-exon bounderies. Reference sequences were obtained from the Ensembl Genome Browser (http:// useast.ensembl.org/index.html). The primers used for PCR amplification were 5'GCTCATTGCAGCTCAGACAC3' and 5'GAGCTGCCTGGAGAAAAATG3' for exon 1 and 5'AAGTAGAGCGTGGGGATGGA3' and 5'GGACTTCTTTCTAGGCTGTGA3' for exon 2. PCR products were 205 and 438 base pairs long, respectively. Reactions conditions were as follows: exon 1 (one cycle of $94{ }^{\circ} \mathrm{C}$ for 10 minutes, then 40 cycles at 94 ${ }^{\circ} \mathrm{C}$ for 15 seconds, $58{ }^{\circ} \mathrm{C}$ for 20 seconds, and $72{ }^{\circ} \mathrm{C}$ for 40 seconds, with final extension at $72{ }^{\circ} \mathrm{C}$ for 4 minutes); exon 2 (one cycle of $94{ }^{\circ} \mathrm{C}$ for 10 minutes, then 35 cycles of at $94{ }^{\circ} \mathrm{C}$ for 30 seconds, $55^{\circ} \mathrm{C}$ for 30 seconds, and $72^{\circ} \mathrm{C}$ for 1 minute). PCR products were directly sequenced using an ABI PRISM BigDye ${ }^{\mathrm{TM}}$ Terminator Cycle Sequencing Ready Reaction 
Kit in an ABI 3730xl DNA Analyzers (Applied Biosystems, CA, USA). Sequences obtained were compaired against the sequences in the Ensembl Genome Browser and two unrelated CEPH (Foundation Jean Dausset-Centre d'Etude du Polymorphisme Humain) controls. We used PolyPhen-2 (Adzhubei et al. 2010) to predict the functional effects of any nonsynonymous single nucleotide changes detected.

\section{Gene Expression Analyses}

Samples-From Argentina, 143 DNA and RNA samples from unrelated individuals living in twelve Patagonia sites (San Carlos de Bariloche, El Bolsón, Esquel, El Maitén, Maquinchao, Ingeniero Jacobacci, Rio Colorado, Choele Choel, Valcheta, Sierra Grande, Santo Antonio Oeste, and General Roca) were studied to determine expression of TRAV4 in whole saliva as described below. These samples are part of the the University of Pittsburgh Center for Craniofacial and Dental Genetics studies. The mean age was 21.7 years (between infants under 1 and 72 years with median of 18 years) and both the Centro de Educación Médica e Investigaciones Clínicas "Norberto Quirno" (CEMIC) and University of Pittsburgh Institutional Review Boards approved the study of these samples and appropriate written informed consent was obtained from all participants (parents provided consent for the participation of individuals 17 years of age and under).

mRNA Expression of TRAV4 in Whole Saliva-Whole saliva RNA samples were used for isolation of total RNA from 143 Argentinean individuals using the RNeasy Micro kit (Qiagen, CA, USA). Total RNA from saliva was successfully isolated from 118 samples. mRNA expression analysis of TRA V4 was performed in real time PCR using SYBR Green chemistry in a 7900HT Real-time PCR system (Applied Biosystems, CA, USA). Primer sequences were forward 5'ATGAGGCAGTGGCGAGAGTG3' and reverse 5'GGCTGGGAAACTGTTGGTAC3'. A PCR product of 175 base pairs was obtained. Products spanned at least one intron, so that cDNA products were distinguishable from potential genomic DNA products. $\beta$-Actin was used as an endogenous control. Reaction conditions were: $50{ }^{\circ} \mathrm{C}$ for 2 minutes, $95^{\circ} \mathrm{C}$ for 10 minutes, 40 cycles at $95^{\circ} \mathrm{C}$ for 15 seconds and $60{ }^{\circ} \mathrm{C}$ for 1 minute, then a dissociation stage of $95^{\circ} \mathrm{C}$ for 15 seconds, $60{ }^{\circ} \mathrm{C}$ for 30 seconds, and $95^{\circ} \mathrm{C}$ for 15 seconds. The quantification of mRNA expression levels relative to $\beta$-Actin was performed by relative quantification or 2DDCT method (Livak and Schmittgen 2001). Differences between low ( $N=73)$ and high $(\mathrm{N}=45)$ caries experience samples were analyzed by using the Student's $t$ test. P $\leq 0.05$ was considered statistically significant. mRNA levels were also compared based on genotypes of the four SNPs found to be associated witht he Filipino families. DNA samples from the same subjects were used and genotypes were generated as described earlier.

\section{Results}

\section{Association Analyses}

From the 48 single nucleotide polymorphisms used for fine-mapping the 14q11.2 locus, four markers were overtransmitted at nominal significance $(0.01 \unlhd \triangleleft 0.05)$ depending on caries experience level (Table 3).

Philippines-Nominal association between TRA V4 markers rs1997532, rs1997533, rs8011979, rs7150049 and caries experience was detected uder the recessive model. The $T$ allele of rs1997532 ( $\mathrm{p}=0.04)$, the $\mathrm{G}$ allele of rs1997533 ( $\mathrm{p}=0.02)$, the T allele of rs8011979 ( $p=0.01)$, and the $G$ allele of $\operatorname{rs} 7150049(p=0.02)$, were associated with low caries experience (Table 3 ), indicating that these alleles may have a protective effect for caries. No strong linkage disequilibrium was detected between these markers based on $\mathrm{D}^{\prime}$ 
and $\mathrm{r}^{2}$ values (data not shown). Haplotype analysis did not improve the single marker analysis results.

Turkey-In the Turkish cohort, we also detected significant association for all four TRAV4 markers initially associated with low caries experience in the Filipinos. The T allele of rs1997532 $(\mathrm{p}=0.0005)$, the $\mathrm{G}$ allele of $\mathrm{rs} 1997533(\mathrm{p}=0.01)$, the $\mathrm{T}$ allele of $\mathrm{rs} 8011979(\mathrm{p}=$ $0.001)$, and the $\mathrm{G}$ allele of $\mathrm{rs} 7150049(\mathrm{p}=0.001)$, were associated with low caries experience (Table 4), indicating that these alleles may have a protective effect for caries.

Guatemala and Brazil-In the Guatemala cohort, we detected significant association between the T allele of TRAV4 rs1997532 (p=0.03) and low caries experience by logistic regression adjusted for sex. No associations were found in the Brazilian cohort from Curitiba, although the sample from Rio de Janeiro showed association between low caries experience and TRAV4 rs7150049 (p=0.05).

\section{Mutation Search}

We found four variants in TRAV4 in six individuals: two silent mutations (S26S and L92L), one intronic variant (C1011-66T), and one missense mutation (Y30R). The missense mutation represents a change from an uncharged polar tyrosine to a basic charged polar arginine (Table 5). PolyPhen-2 predicts this change as probably damaging to the TRAV4 protein.

\section{TRAV4 Expression Analyses in Whole Saliva}

We observed differential expression of $T R A V 4$ mRNA levels based on individual genotype (Figure 1). When TRAV4 expression was analyzed in subjects with low caries experience carrying at least one copy of the less frequent allele of each marker, statistically significant higher expression of TRAV4 was seen in children younger than 17 years of age (Figure 2).

\section{Discussion}

It is not uncommon to encounter caries-free individuals, that despite never having gone to the dentist, nor paid special attention to diet or adequate oral hygiene. This evidence suggests that there is an underlying biological mechanism that inhibits one or more factors that increase individual's risk to caries. One plausible mechanism is the influence on bacterial colonization, which likely involves the host immune system.

In this study, 2,453 individuals were studied to assess the association and potential role of $14 q 11.2$ in caries. Our previous genome-wide linkage scan has identified the 14q11.2 locus as linked to low caries experience in Filipino families (Vieira et al. 2008a). We fine mapped the $14 \mathrm{q} 11.2$ region in 477 subjects from 72 pedigrees with similar cultural and behavioral habits and limited access to dental care living in the Philippines. For replication purposes a total of 1,446 independent subjects from four different populations were analyzed.

Statistically significant associations were found between low caries experience and markers in the TRAV4 gene. We were able to replicate these results in populations with higher caries experience from underserved areas. Direct sequencing of the TRAV4 gene in 22 individuals with low caries experience revealed one missense mutation (Y30R) that changes an uncharged polar to a basic charged polar and this alteration could impact TRAV4 function. However, we believe this finding alone does not explain our relatively modest association results, since the frequency of the mutation in the studied Filipino population is $0.19 \%$. The frequency is higher in the Filipinos that carry two copies of the haplotype comprised of the four SNPs we found associated with low caries experience $(4.5 \%)$ but the frequency of Filipinos homozygous for this haplotype is $4.1 \%$. Additional variants in TRAV4 may exist 
to explain our association results, since the TRAV4 Y30R mutation alone cannot. We checked the location of the four associated SNPs against the aligned consensus sequences of the TRAV genes (Koop et al. 1994; data not shown) and none of the SNPs were located in these sequences, which suggests that these SNPs are not functional. TRAV4 appears to be expressed in higher levels in younger individuals with lower caries experience and this expression is a reflection of carrying specific SNP variants. Our results suggest TRAV4 may have a role in protecting against caries.

Correction for multiple comparisons in single marker analyses was performed using the SNP spectral decomposition (SpD) method (Nyholt 2004). We chose this method over the popular Bonferroni correction to avoid overcorrecting our results and reducing power since the genetic markers we studied were purposely chosen to avoid complete linkage disequilibrium. While concerned about multiple testing, we still decided to further explore the four nominal significant statistical results in the Filipino families (Table 3), since the original linkage analysis suggested linkage to the locus (Vieira et al. 2008a). If we had ignored those, we would not have found the statistically significant associations in the Turkish and Guatemalans and would not have performed the expression experiments. Our previous work on other craniofacial anomalies has shown that known associations will be missed if we ignore observed trends for association in the data (Vieira et al. 2008b). The lack of association in the Brazilians may be due to their less severe caries experience and better oral health (Table 1). We could still see a trend for association for one of the markers and we may be able to detect an association if sample sizes were larger for this study population. In the future, it may be helpful to compare caries free with low caries and high caries experience individuals, which may allow us to discriminate possible different influences that younger and older patients may have in regards o genetic factors.

TRAV genes play a role in immune response and that is the mechanism that may relate $T R A V 4$ genetic variation with caries susceptibility. T helper and T killer cells play a critical role in the vertebrate immune response. There are two types of T-cell receptors, $a \beta$ and $\gamma \delta$. The $a, \beta, \delta$, and $\gamma$ polypeptide chains are made up of variable (antigen recognition) and constant (membrane attachment and activation) regions (Koop et al. 1994). The variable regions are further encoded by multiple variable (V), diversity (D), and joining (J) gene segments for the $\alpha$ and $\gamma$ chains. These segments undergo somatic DNA rearrangements during lymphocyte differentiation to generate contiguous $\mathrm{V} / \mathrm{J}$ or $\mathrm{V} / \mathrm{D} / \mathrm{J}$ genes. T-cell receptor alpha variable (TRAV) genes (Figure 3 ) have their RNA transcripts spliced and translated to form one complete polypeptide chain. The many functional T-cell receptors and addition and/or replacements of nucleotides at the junctions of these genes enables them to recognize the vast array of potential antigenic peptides (Lafaile et al. 1989; Meier and Lewis 1993). The number of TRAV segments in the human genome is 54, of which 44 are functional (expressed protein), eight are pseudogenes (no expressed protein), and two are not yet characterized. The human TRAV genes are grouped into more than 30 subgroups. The TRAV genes are linked to 61 TCR a-chain J gene segments (TRAJ1 to TRAJ61), of which eleven are functional, but the TRAJ genes cluster in a region that is $3^{\prime}$ to both the TRAV genes and all of the TCR $\delta$-chain segments, including the variable (TRDV), diversity (TRDD), joining (TRDJ), and constant (TRDC) region segments. The TRAJ genes are found $5^{\prime}$ to the single TCR a-chain C segment (Ceri and Mody, 2004).

The exact mechanism by which TRAV genes, including $T R A V 4$, could influence oral health and caries is not known. Similar to what we see in cancer (He et al. 2012), TRAV genes may be related to the diversity of oral antigens and the likely differential immune responses of the host. Our data showed that TRAV4 mRNA can be detected in whole saliva and the same genetic variants we found associated with low caries experience showed variable expression depending of the age of individuals that have low caries experience. These are intriguing 
findings and suggest that caries needs to be considered a lifelong threat that changes overtime. Individuals with primary dentition or with recently erupted permanent dentition are thought to be particularly susceptible to caries attack. Typically the accumulation of disease experience, as reflected by DMFT or DMFS scores, slows down as one grows older, although many individuals may suffer from repetitive bouts of disease affection. These assumptions are indirectly supported by our results, which showed statistically significant associations between TRAV4 genetic variation and low caries experience in the youngest cohort study (the Turkish). The results continued to support this association in the cohorts from more underserved areas (Filipinos and Guatemalans), although no associations were found in the Brazilian cohort from Curitiba, which in contrast to the other studied groups, is the least affected by caries. Since TRAV4 appears to have higher expression in younger individuals with low caries experience in comparison with adults with low caries experience, we hypothesize that this gene is more likely to play a role in caries at younger ages and not so much later in life. In light of the high complexity of the TRAV locus, it is possible that other genes in the region may contribute to the association results of this study. Future research should focus on examining all the genes in the TRAV4 locus to search for genetic variants that may be linked to mechanisms that naturally protect individuals against the caries attack.

\section{Acknowledgments}

We would like to thank the individuals that participated in this study for their support. Sarah Vinski provided administrative support. This research is supported by NIH grants R01-DE018914 and R01-DE016148. Study subjects in Guatemala were recruited through collaboration with Children of the Americas (http:// www.childrenoftheamericas.org/).

\section{References}

Abecasis GR, Cookson WO. GOLD - Graphical overview of linkage disequilibrium. Bioinformatics. 2000; 16:182-183. [PubMed: 10842743]

Adzhubei IA, Schmidt S, Peshkin L, Ramensky VE, Gerasimova A, Bork P, Kondrashov AS, Sunyaev SR. A method and server for predicting damaging missense mutations. Nat Methods. 2010; 7:248249. [PubMed: 20354512]

Barrett JC, Fry B, Maller J, Daly MJ. Haploview: analysis and visualization of LD and haplotype maps. Bioinformatics. 2005; 21:263-265. [PubMed: 15297300]

Bretz WA, Corby PM, Schork NJ, Robinson MT, Coelho M, Costa S, Melo Filho MR, Weyant RJ, Hart TC. Longitudinal analysis of heritability for dental caries traits. J Dent Res. 2005; 84:10471051. [PubMed: 16246939]

Brancher JA, Pecharki GD, Doetzer AD, Medeiros KG, Cordeiro CA Jr, Sotomaior VS, Bauer P, Trevilatto PC. Analysis of polymorphisms in the lactotransferrin gene promoter and dental caries. Int J Dent. 2011; 2011:571726. [PubMed: 22190933]

Bretz WA, Corby PM, Melo MR, Coelho MQ, Costa SM, Robinson M, Schork NJ, Drewnowski A, Hart TC. Heritability estimates for dental caries and sucrose sweetness preference. Arch Oral Biol. 2006; 51:1156-1160. [PubMed: 16934741]

Ceri, H.; Mody, C. The T-cell receptor. In: Pier, GB.; Lyczak, JB.; Wetzler, LM., editors. Immunology, infection, and immunity. 1. American Society for Microbiology Press; Washington D.C: 2004. p. 297-314.

Conry JP, Messer LB, Boraas JC, Aeppli DP, Bouchard TJ Jr. Dental caries and treatment characteristics in human twins reared apart. Arch Oral Biol. 1993; 38:937-943. [PubMed: 8297257]

Deeley K, Letra A, Rose EK, Brandon CA, Resick JM, Marazita ML, Vieira AR. Possible association of amelogenin to high caries experience in a Guatemalan-Mayan population. Caries Res. 2008; 42:8-13. [PubMed: 18042988] 
Fisher-Owens SA, Gansky SA, Platt LJ, Weintraub JA, Soobader MJ, Bramlett MD, Newacheck PW. Influences on children's oral health: a conceptul model. Pediatrics. 2007; 120:e510-520. [PubMed: 17766495]

Gao XL, Hsu CY, Xu Y, Hwarng HB, Loh T, Koh D. Building caries risk assessment models for children. J Den Res. 2010; 89:637-643.

He XY, Yang WM, Tang WT, Ma R, Sun YP, Wang P, Yao XS. TRAV gene expression in PBMCs and TILs in patients with breast cancer analyzed by a DNA melting curve (FQ-PCR) technique for TCR alpha chain CDR3 spectrapyng. Neoplasma. 2012; 59:693-699. [PubMed: 22862170]

Horvath S, Xu X, Laird NM. The family based association test method: strategies for studying general genotype--phenotype associations. Eur J Hum Genet. 2001; 9:301-306. [PubMed: 11313775]

Koop BF, Rowen L, Wang K, Kuo CL, Seto D, Lenstra JA, Howard S, Shan W, Deshpande P, Hood L. The human T-cell receptor TCRAC/TCRDC (Ca/C 8 ) region: Organization, sequence, and evolution of $97.6 \mathrm{kn}$ of DNA. Genomics. 1994; 19:478-493. [PubMed: 8188290]

Lafaille JJ, DeCloux A, Bonneville M, Takagaki Y, Tonegawa S. Junctional sequences of T cell receptor $\gamma \delta$ genes: Implications for $\gamma \delta \mathrm{T}$ cell lineages and for a novel intermediate of $\mathrm{V}$-(D)-J joining. Cell. 1989; 59:859-870. [PubMed: 2590942]

Livak KJ, Schmittgen TD. Analysis of relative gene expression data using real-time quantitative PCR and the 2(-Delta Delta C(T)). Methods. 2001; 25:402-408. [PubMed: 11846609]

Meier JT, Lewis SM. P nucleotides and V(D)J recombination: A fine-structure analysis. Mol Cell Biol. 1993; 13:1078-1092. [PubMed: 8380891]

Murray JC, Daack-Hirsch S, Buetow KH, Munger R, Espina L, Paglinawan N, Villanueva E, Rary J, Magee K, Magee W. Clinical and epidemiological studies of cleft lip and palate in the Philippines. Cleft Palate Craniofac J. 1997; 34:7-10. [PubMed: 9003905]

Nariyama M, Shimizu K, Uematsu T, Maeda T. Identification of chromosomes associated with dental caries susceptibility using quantitative trait locus analysis in mice. Caries Res. 2004; 38:79-84. [PubMed: 14767162]

Nyholt DR. A simple correction for multiple testing for single-nucleotide polymorphisms in linkage disequilibrium with each other. Am J Hum Genet. 2004; 74:765-769. [PubMed: 14997420]

Patir A, Seymen F, Yildirim M, Deeley K, Cooper ME, Marazita ML, Vieira AR. Enamel formation genes are associated with high caries experience in Turkish children. Caries Res. 2008; 42:394400. [PubMed: 18781068]

Powell LV. Caries prediction: a review of the literature. Community Dent Oral Epidemiol. 1998; 26:361-371. [PubMed: 9870535]

Purcell S, Neale B, Todd-Brown K, Thomas L, Ferreira MA, Bender D, Maller J, Sklar P, de Bakker PI, Daly MJ, Sham PC. PLINK: a toolset for whole-genome association and population-based linkage analysis. Am J Hum Genet. 2007; 81:559-575. [PubMed: 17701901]

Shimizu T, Deeley K, Briseño-Ruiz J, Faraco IM Jr, Poletta FA, Brancher JA, Pecharki GD, Küchler EC, Tannure PN, Lips A, Vieira TC, Patir A, Yildirim M, Mereb JC, Resick JM, Brandon CA, Cooper ME, Seymen F, Costa MC, Granjeiro JM, Trevilatto PC, Orioli IM, Castilla EE, Marazita ML, Vieira AR. Fine-Mapping of 5q12.1-13.3 Unveils New Genetic Contributors to Caries. Caries Res. 2013; 47:273-283. [PubMed: 23363935]

Suzuki N, Kurihara Y. Dental caries susceptibility in mice is closely linked to the H-2 region on chromosome 17. Caries Res. 1998; 32:262-265. [PubMed: 9643368]

Tannure PN, Küchler EC, Lips A, Costa MC, Luiz RR, Granjeiro JM, Vieira AR. Genetic variation in MMP20 contributes to higher caries experience. J Dent. 2012; 40:381-386. [PubMed: 22330321]

Vieira AR, Marazita ML, Goldstein-McHenry T. Genome-wide scan finds suggestive caries loci. J Dent Res. 2008a; 87:435-439. [PubMed: 18434572]

Vieira AR, McHenry TG, Daack-Hirsch S, Murray JC, Marazita ML. Candidate gene/loci studies in cleft lip/palate and dental anomalies finds novel susceptibility genes for clefts. Genet Med. 2008b; 10:688-674.

Wang X, Shaffer JR, Weyant RJ, Cuenco KT, DeSensi RS, Crout R, McNeil DW, Marazita ML. Genes and their effects on dental caries may differ between primary and permanent dentitions. Caries Res. 2010; 44:277-284. [PubMed: 20516689] 
Werneck RI, Lázaro FP, Cobat A, Grant AV, Xavier MB, Abel L, Alcaïs A, Trevilatto PC, Mira MT. A major gene effect controls resistance to caries. J Dent Res. 2011; 90:735-739. [PubMed: 21364090]

World Health Organisation. Oral health surveys - Basic methods. 4. Geneva: World Health Organisation; 1997.

World Health Organisation. The world oral health report 2003. 2003. 

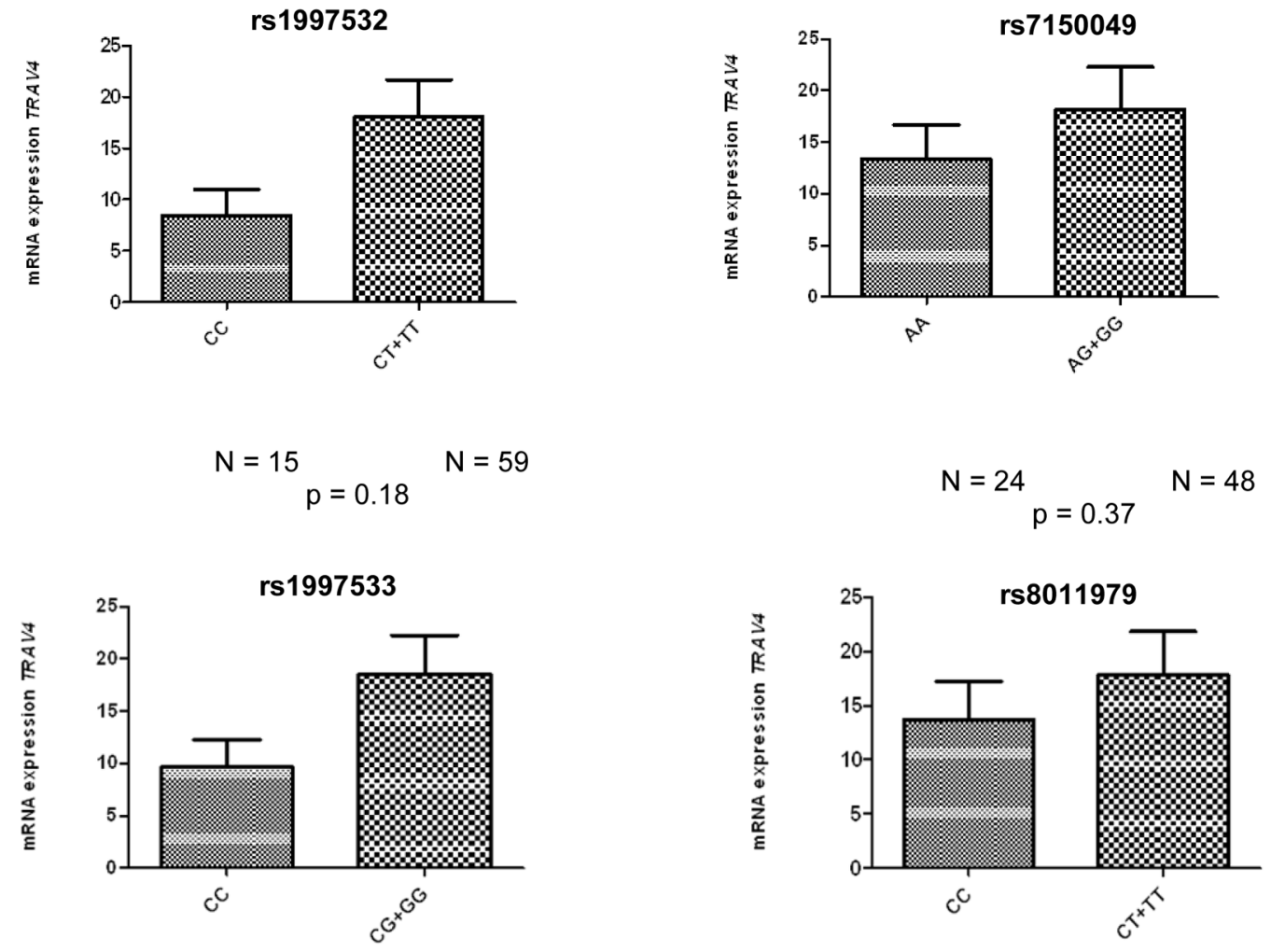

$$
N=17_{p=0.05} N=56
$$$$
N=22_{p=0.44} N=50
$$

Figure 1.

$T R A V 4$ mRNA expression levels in whole saliva based on marker genotype and allele frequencies. 

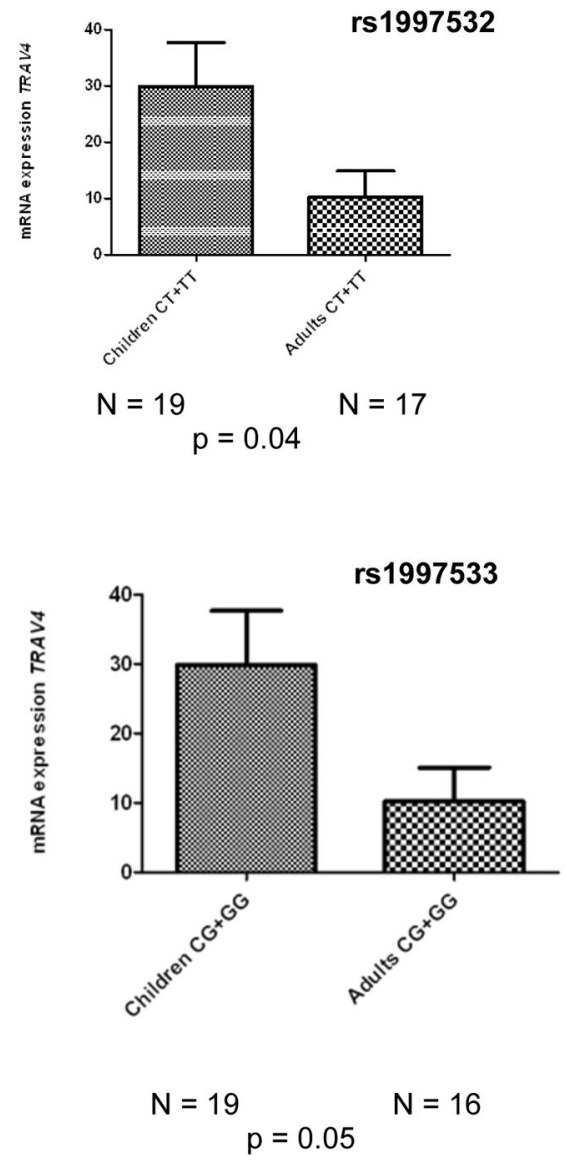
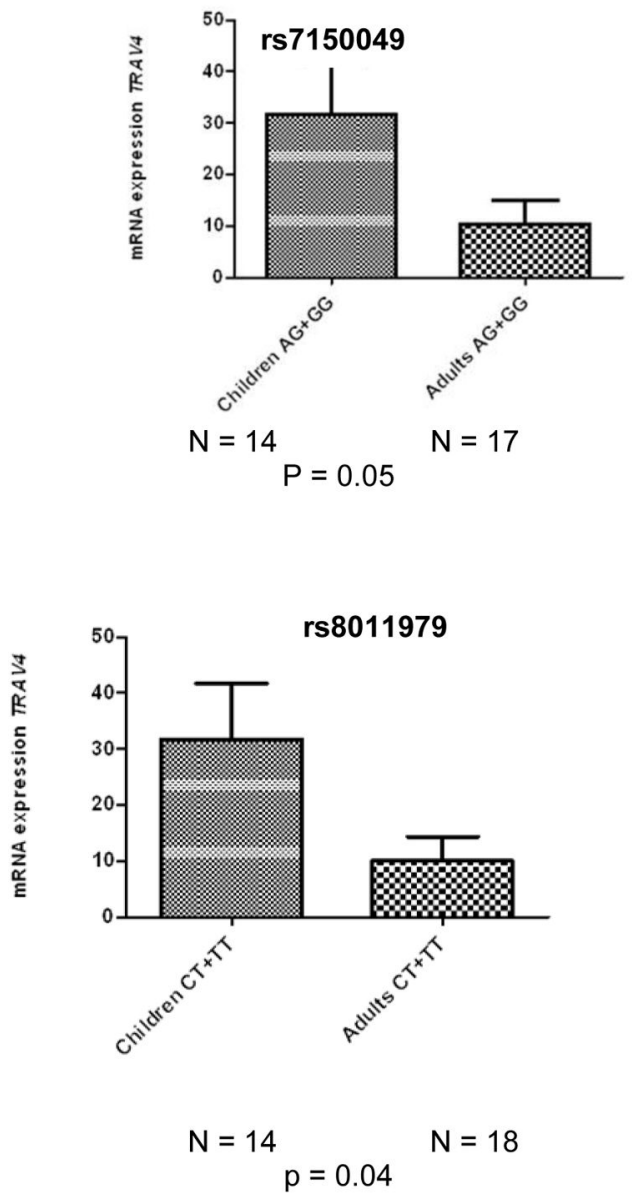

Figure 2.

TRA V4 mRNA expression levels in whole saliva based on marker genotype (at least one copy of the minor allele), caries experience (low experience), and age (individuals 17 years old or younger versus adults). 


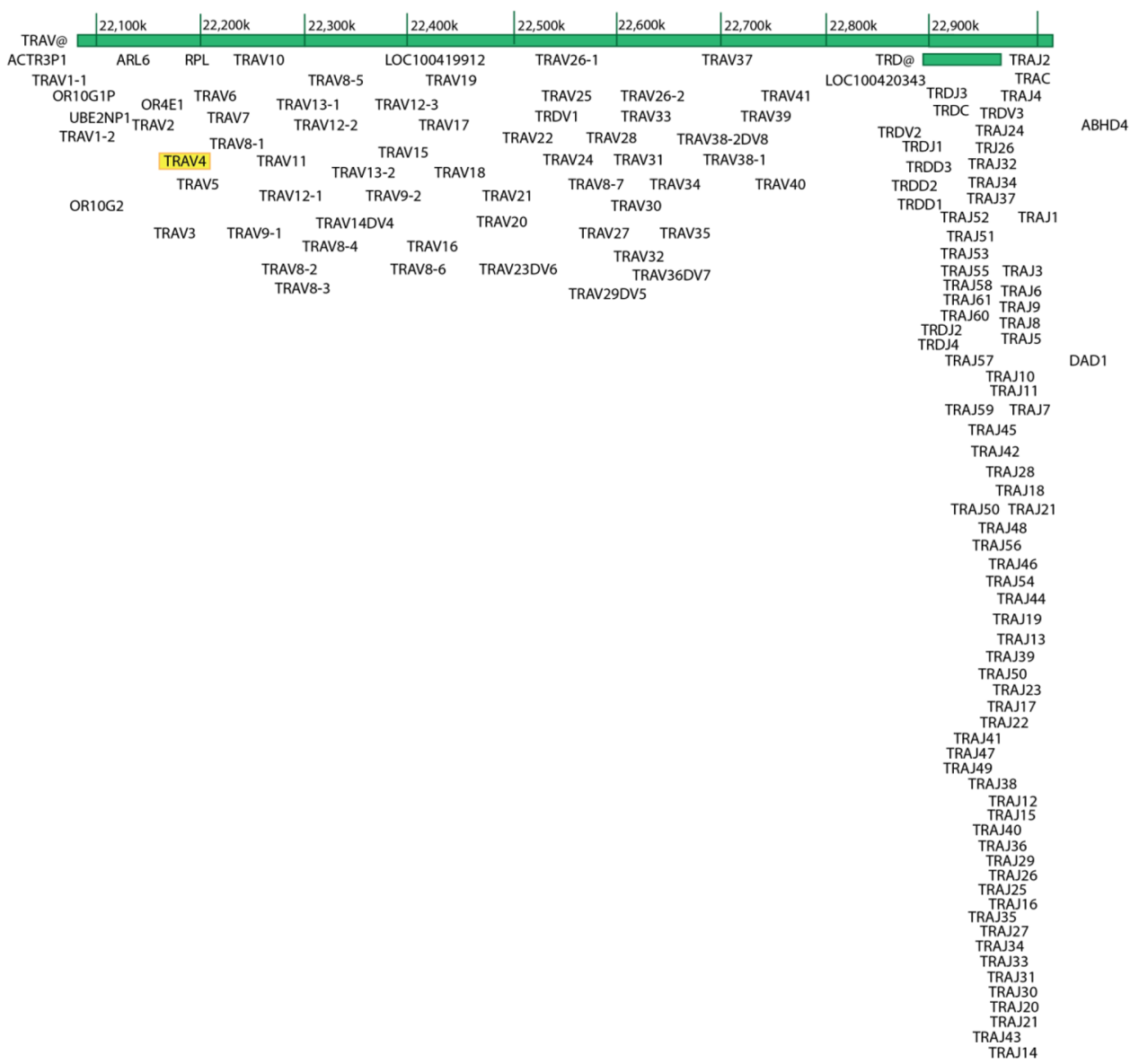

Figure 3.

The complexity of the TRAV4 locus. 


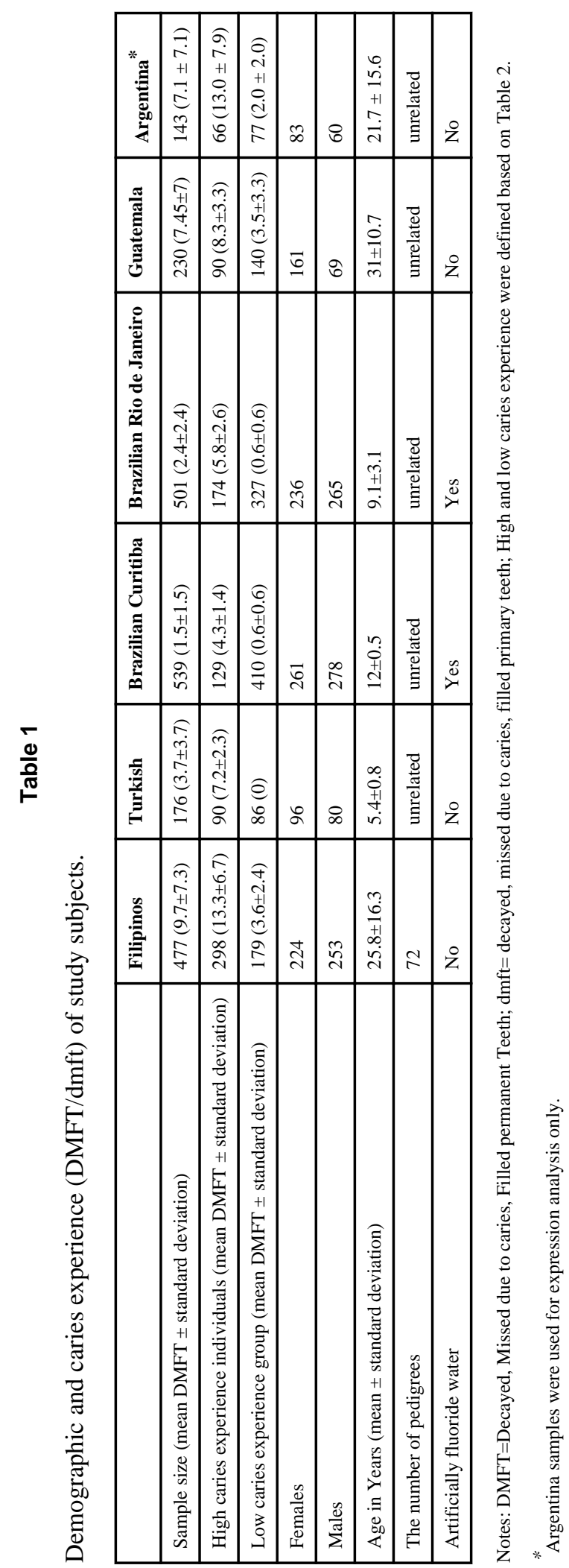

Hum Genet. Author manuscript; available in PMC 2014 September 01. 
Table 2

Definition of caries experience ${ }^{*}$ based on age and DMFT (Decayed, Missing due to caries, Filled Teeth) scores.

\begin{tabular}{|l|l|l|}
\hline & Number of Individuals & DMFT \\
\hline Caries Experience Level & 477 & \\
\hline Children (up to 12 years of age) & 115 & \\
\hline Low caries experience & 26 & $0-2$ \\
\hline High caries experience & 89 & 3 or higher \\
\hline Teenagers (from 13 to 19 years of age) & 104 & \\
\hline Low caries experience & 44 & $0-5$ \\
\hline High caries experience & 60 & 6 or higher \\
\hline Adults (20 years of age and older) & 258 & \\
\hline Low caries experience & 99 & $0-8$ \\
\hline High caries experience & 159 & 9 or higher \\
\hline
\end{tabular}

Based on Vieira et al. (2008). 


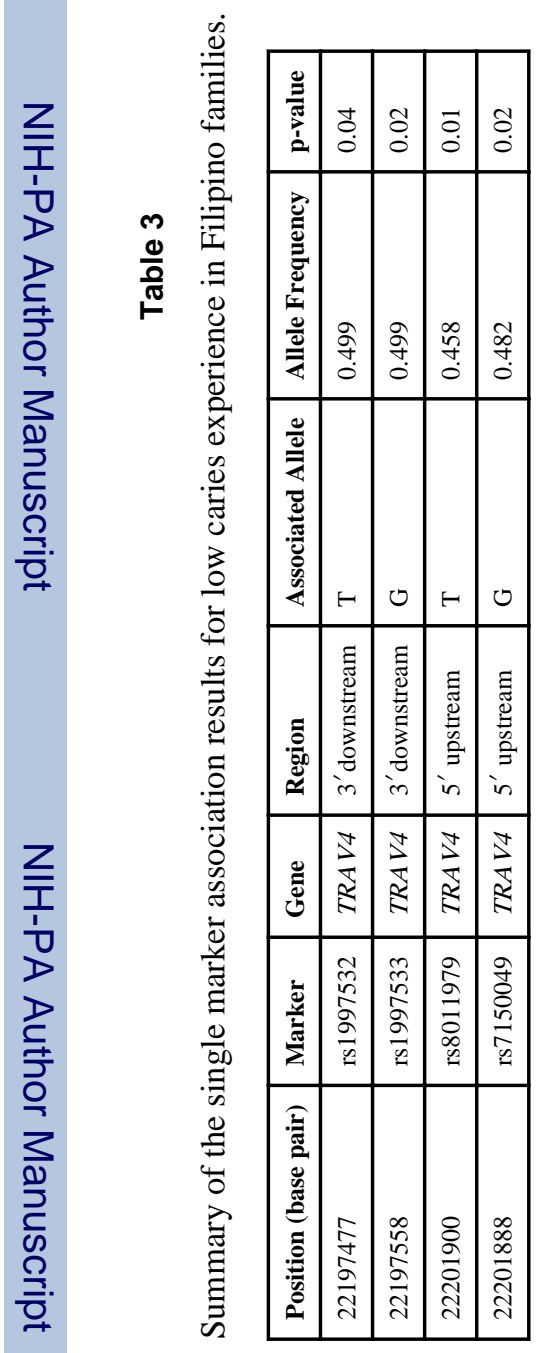




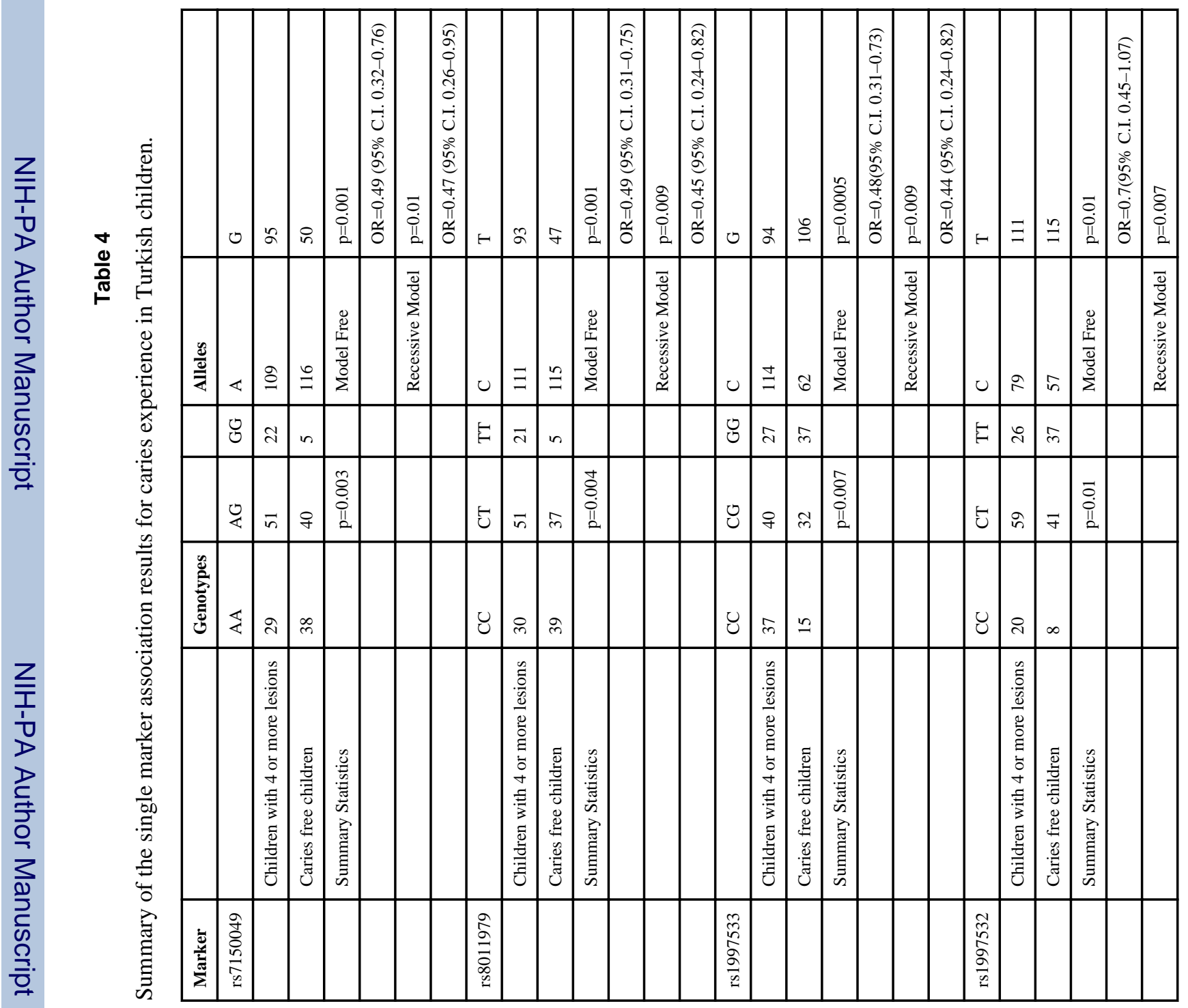




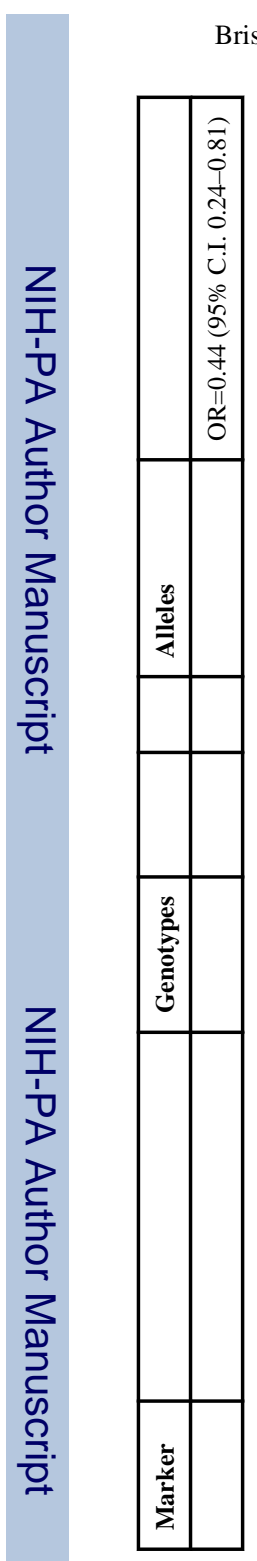

Briseño-Ruiz et al

Page 19 
Table 5

Summary of the results of the TRAV4 mutation search.

\begin{tabular}{|l|l|l|l|l|}
\hline Location & Base Pair Position & Protein Position & Type of Mutation & Frequency \\
\hline Exon 1 & A77C & S26S & Silent & $4 / 22$ \\
\hline Exon 1 & T88A & Y30R & Missense & $1 / 22$ \\
\hline Exon 1 & A276G & L92L & Silent & $2 / 22$ \\
\hline Intron 1 & C1011-66T & - & - & $3 / 22$ \\
\hline
\end{tabular}

